\title{
SHAPES OF AN AIR TAYLOR BUBBLE IN STAGNANT LIQUIDS INFLUENCED BY DIFFERENT SURFACE TENSIONS
}

\author{
B. LERTNUWAT \\ Department of Mechanical Engineering, Faculty of Engineering \\ Chulalongkorn University, Bangkok, 10330 THAILAND \\ E-mail: Boonchai.L@Chula.ac.th
}

\begin{abstract}
The aim of this work is to propose an empirical model for predicting shapes of a Taylor bubble, which is a part of slug flows, under different values of the surface tension in stagnant liquids by employing numerical simulations. The $k-\varepsilon$ turbulence model was used in the framework of finite volume method for simulating flow fields in a unit of slug flow and also the pressure distribution on a Taylor bubble surface. Assuming that an air pressure distribution inside the Taylor bubble must be uniform, a grid search method was exploited to find an appropriate shape of a Taylor bubble for six values of surface tension. It was found that the shape of a Taylor bubble would be blunter if the surface tension was increased. This was because the surface tension affected the Froude number, controlling the flow around a Taylor bubble. The simulation results were also compared with the Taylor bubble shape, created by the Dumitrescu-and-Taylor model and former studies in order to ensure that they were consistent. Finally, the empirical model was presented from the simulation results.
\end{abstract}

Key words: Dumitrescu-and-Taylor model, Froude number, Surface tension, Taylor bubble, Turbulence.

\section{Introduction}

A slug flow is a kind of the two-phase gas-liquid flow, e.g. bubble flow, slug flow, churn flow, annular flow and dispersed flow which appear in different conditions, depending on the gas-to-liquid ratio of the mixture. The slug flow is often found in engineering application, for example in a petroleum pipeline. When a gas-liquid petroleum mixture is sucked from a deep well, the static pressure of the mixture in the pipeline will be reduced due to the altitude change, resulting in the expansion of the gas part of the mixture. The mixture then forms a pattern of the slug flow.

As illustrated in Fig.1a, a slug flow consists of three main components, namely: liquid slugs, falling films and elongation bubbles (so-called Taylor bubbles). In many former studies, slug flows were usually considered as a unit for the sake of simplicity. A unit of a slug flow is comprised of a liquid slug, a falling film and a Taylor bubble as shown in Fig.1b. The velocity of a Taylor bubble $\left(w_{b}\right)$, in Fig.1b, can be estimated with

$$
w_{b}=w_{t}+C_{l} w_{l}+C_{g} w_{g}
$$

where $C_{l}$ and $C_{g}$ are between 1.0 and 2.2, depending on the magnitudes of $w_{l}$ and $w_{g}$ [1-2]. In case of a stagnant fluid, i.e., both $w_{l}$ and $w_{g}$ are equal to zero, the velocity of the Taylor bubble yields

$$
w_{b}=w_{t}=F r_{D} \sqrt{g D_{p}} .
$$

According to [3], the Froude number in Eq.(1.2) is a function of both $R e_{D}$ and $E o_{D}$, namely 


$$
F r_{D}^{2}=\frac{0.0089\left(1+41 / E o_{D}^{1.96}\right)^{-4.63}}{0.0725+\left(1-0.11 \operatorname{Re}_{D}^{0.33}\right) / \operatorname{Re}_{D}}
$$

Results, calculated with Eq.(1.3), agree very well with the data obtained from [4] and overcome inaccuracies at intermediate Morton numbers $(\mathrm{M})$. Herein

$$
\begin{aligned}
& R e_{D}=\rho_{l} w_{t} D_{p} / \mu_{l}, \\
& E o_{D}=\left(\rho_{l}-\rho_{g}\right) g D_{p}^{2} / \sigma
\end{aligned}
$$

and

$$
M=\left(\rho_{l}-\rho_{g}\right) g \mu_{l}^{4} /\left(\rho_{l}^{2} \sigma^{3}\right) .
$$

Although the Taylor bubble drifts upward with respect to an observer who stands on the earth surface, the flow field around the Taylor bubble is usually considered with respect to the nose of the Taylor bubble as depicted in Fig. 1c by the reason of simplicity.

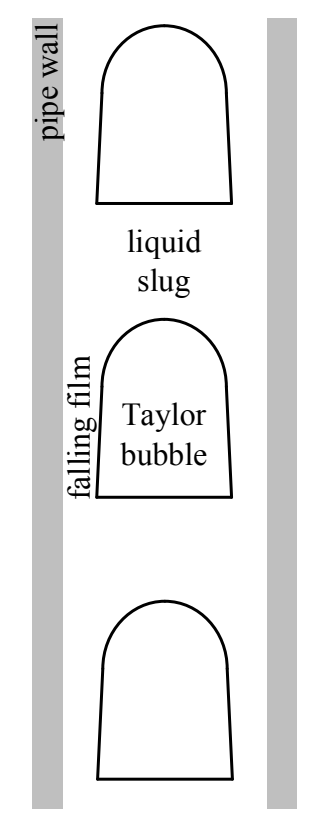

(a)

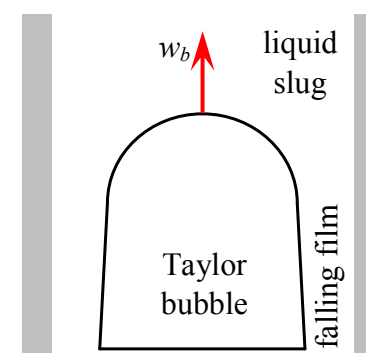

(b)

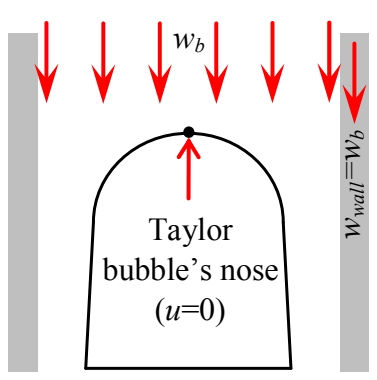

(c)

Fig.1. Schematic diagrams (a) a typical slug flow, (b) a unit of a slug flow relative to the pipe wall and (c) a unit of a slug flow relative to the nose of the Taylor bubble.

The shape of the Taylor bubble which apparently looks similar to a bullet was found that it likely affected the pressure drop in the flow by generating vertices behind itself [5-8]. The consequence of these vertices was the interaction between two successive Taylor bubbles. Since the shape of the Taylor bubble dominates the strength of the vertices, many studies have been done to predict the shape of the Taylor bubble under different conditions. Nogueira et al. [9] performed experiments for a wide range of liquid viscosity 
(from 0.001 to $1.5 \mathrm{~Pa}$-s) in order to find out the different shapes of the Taylor bubble. Bugg et al. [10] showed the different shapes of the Taylor bubble under the conditions that $10^{-12} \leq M \leq 10$ and $10 \leq E o \leq 100$ by using the Volume-of-Fluid (VOF) method which was an interface-capturing method. In 1990, Mao and Dukler [11] revealed the influence of the co-currant liquid speed $\left(w_{l}\right)$ on the shape of the Taylor bubble with an interface-tracking method which considered the tension effect on the gas-liquid interfacial surface but neglected the effect of the normal stress. While in 1991, they showed the effect of both viscosity and surface tension on the shape of the Taylor bubble by using the same program code, upgraded with the $k-\varepsilon$ turbulence model [12]. Kawaji et al. [13] used the VOF method to study the speed of the Taylor bubble and confirmed that the Taylor bubble moved faster when it moved off the tube axis since the shape of the Taylor bubble became asymmetric, leading to a lower drag force. Smith et al. [14] stated that the diameter of the tube, where the Taylor bubble existed, would not affect the shape of the Taylor bubbles if the tube diameter was smaller than $3 \mathrm{~mm}$. The simulation results in [15] showed that increasing the Capillary number $(\mathrm{Ca})$ resulted in an increment of the liquid film thickness (a slenderer shape of the Taylor bubble) and the sharpness of the bubble nose. These previous studies were done to show how the shape of the Taylor bubble changed with various conditions but no predicting model of the Taylor bubble shape was presented. The objective of this work is, thus, to propose an empirical model for predicting the shape of the Taylor bubble under different values of the surface tension on the gas-liquid interface in stagnant liquids.

\section{Theory}

As a matter of fact, the shape of a Taylor bubble has long been modeled. It was simply modeled as a capsule, consisted of two hemispherical caps and a cylinder body in [16]. A more complicated model was presented in [17], consisting of 2 equations, i.e.

$$
\left(\frac{R_{b}}{R_{p}}\right)^{2}=\frac{\Delta z}{R_{p}}\left(\frac{3}{2}-\frac{\Delta z}{R_{p}}\right) \quad \text { when } \quad \frac{\Delta z}{R_{p}} \leq 0.5
$$

and

$$
\left(\frac{R_{b}}{R_{p}}\right)^{2}=1-F r_{D}\left(\frac{R_{p}}{\Delta z}\right)^{0.5} \quad \text { when } \quad \frac{\Delta z}{R_{p}}>0.5
$$

Herein, Eq. (2.1) is Dumitrescu's model which is derived from the potential flow theory [18] and used for predicting the shape of a Taylor bubble within the region of the bubble nose. And Eq.(2.2) is Taylor's model which is used for predicting the rest of the bubble shape. The joint between Eq.(2.1) and Eq.(2.2) is set at $\Delta z=0.5 R_{P}$, suggested by Nogueira et al. [9]. Although, shapes of a Taylor bubble created by the Dumitrescu-and-Taylor model look more natural, they are still different from reality. This is because the model omits the influence of viscosity and the joint between these two equations makes a discontinuity on the shape of a Taylor bubble. that is

Lertnuwat [19] has proposed a model to erase the discontinuity in the Dumitrescu-and-Taylor model,

$$
\frac{R_{b}}{D_{p}}=\frac{1}{2}\left[1-\left(\frac{\beta w_{b}^{2}+\delta}{2 g \Delta z+\delta}\right)^{0.5}\right]^{0.5}
$$

where 


$$
\beta=\alpha_{1}\left(1-e^{\alpha_{2} \Delta z / D_{p}}\right)
$$

Shapes of a Taylor bubble, created from Eq.(2.3), can be adjusted to be slenderer or blunter by varying the values of $\alpha_{1}$ and $\alpha_{2}$ in Eq.(2.4). The appropriate values of $\alpha_{1}$ and $\alpha_{2}$ may be determined by a numerical method, explained in the next session.

\section{Computational setup}

Owing to the assumption that a flow is symmetric around the pipe centerline, the computation domain is just half a unit of the slug flow as shown in Fig.2a. It was found that the slug length $\left(L_{s}\right)$ was between $10 D_{p}$ and $20 D_{p}$, independent of the flow condition [20-22], whereas the Taylor bubble length $\left(L_{b}\right)$ was strongly dependent on $D_{p}$ and $w_{b}$ [20-21, 23]. However, the Taylor bubble length was found between $2 D_{p}$ and $11 D_{p}$ [12]. According to the data from the aforementioned references, the slug length $\left(L_{s}\right)$ was set to be $15 D_{p}$ and the Taylor bubble length $\left(L_{b}\right)$ was set to be $5 D_{p}$.

Taylor bubbles were usually observed in pipes, ranging from very-small-size pipes as capillary tubes $[14-15,24]$ to middle-size pipes $\left(D_{p}<0.1 \mathrm{~m}\right)$ [25-26]. This was because, in a $10 \mathrm{~cm}$ pipe, bubbly flows underwent a regime transition to churn-turbulence (not to slug flows as typically observed in smaller diameter pipes) [27]. Hence the pipe diameter $\left(D_{p}\right)$ was set to be $0.05 \mathrm{~m}$ in this study.

The upper horizontal boundary of the computational domain was controlled by a velocity inlet boundary condition with a velocity $\left(w_{b}\right)$ whose direction is $\boldsymbol{z} \boldsymbol{z}$. A pressure outlet boundary condition was posed on the lower horizontal boundary of the computational domain with a fixed pressure, equal to $100 \mathrm{kPa}$. The pipe wall on the right hand side was posed with a no-slip condition and the velocity of the pipe wall is equal to $-w_{b}$ with respect to the given $\boldsymbol{z}$ axis. A symmetry boundary condition was posed along the upper left side of the computational domain which was the pipe centerline. While the lower left side of the computational domain, which was the interface between the falling film and the Taylor bubble, was assumed to be a free surface boundary.

Figure $2 \mathrm{~b}$ shows the gridline employed in this study. The two horizontal boundaries (upper and lower ones) were placed with 16 gridlines along the $r$ axis, whereas there were totally 161 gridlines placed on the vertical boundaries. This set of gridlines was separated into two groups, i.e., 86 gridlines, which were drawn from the pipe centerline, were in the first group and the other group consisted of the remaining 75 gridlines, drawn from the Taylor bubble surface.

Since most of fluid mixtures, exploited in former studies, were air and water at $25^{\circ} \mathrm{C}$ and $100 \mathrm{kPa}$. The fluid properties, used in this study, were set to be that $\rho_{g}=1.18 \mathrm{~kg} / \mathrm{m}^{3}, \rho_{l}=998 \mathrm{~kg} / \mathrm{m}^{3}$ and $\mu_{l}=$ $0.891 \times 10^{-3}$ Pa-s. While the surface tension on the Taylor bubble surface had to be varied between 0.001 and $0.200 \mathrm{~N} / \mathrm{m}$ to investigate its influence on the Taylor bubble shape and to assure that Reynolds number in the falling film, i.e.

$$
\operatorname{Re}_{f i l m}=\rho_{l} \bar{w}_{f i l m} \delta_{f i l m} / \mu_{l} \approx \rho_{l} w_{t} D_{p} /\left(4 \mu_{l}\right),
$$

must be greater than 400 . This made all the entire liquid flow in the falling film turbulent for every investigating conditions [28]. 


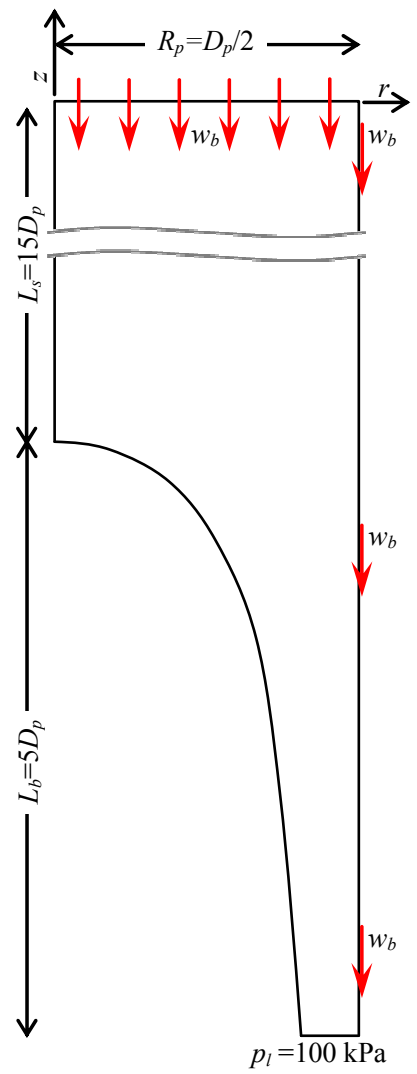

(a)

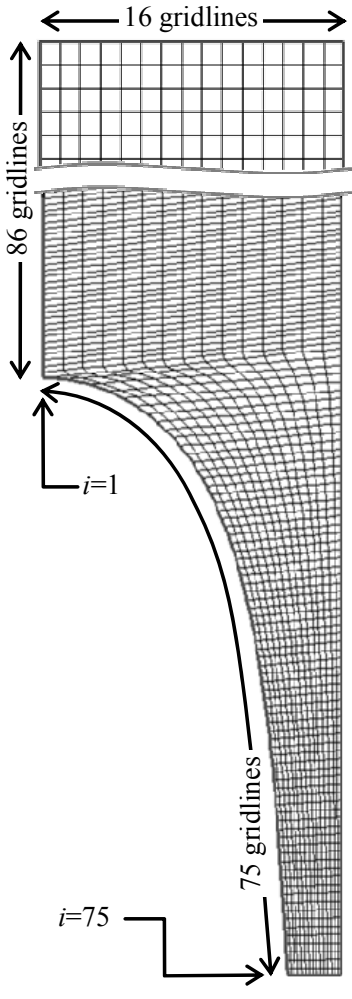

(b)

Fig.2. Computational domain and employed gridlines.

Since all flows in the falling film, studied in this work, were turbulent, the $k-\varepsilon$ model was employed. The simulation code, used in this study, was developed from a program code, given in [29]. The implicit pressure-correction method on the finite volume framework with second order spatial accuracy was utilized for developing the simulation code.

\section{Solution procedure}

Static pressure of any inviscid gas inside a bubble ideally will be constant if the average static pressure of the gas is much greater than the hydrostatic pressure difference $\left(\rho_{g} g \Delta z\right)$ of the gas. This means that along the appropriate shape of a Taylor bubble which is created by Eq.(2.3) and Eq.(2.4) with the appropriate values of $\alpha_{1}$ and $\alpha_{2}$, the distribution of the air pressure inside a Taylor bubble which is related to the liquid pressure of the flow outside the Taylor bubble as

$$
\left.p_{g}\right|_{b s}=\left.p_{l}\right|_{b s}+\sigma \frac{1}{R_{b s}}-\left.2 \mu_{l}\left(\frac{\partial V_{n}}{\partial n}\right)_{l}\right|_{b s}
$$

must be uniform. Herein, the radius of curvature $\left(R_{b s}\right)$ of the Taylor bubble shape can be calculated as follows 


$$
\frac{1}{R_{b s}}=\frac{1}{R_{b s 1}}+\frac{1}{R_{b s 2}}
$$

in which

$$
\begin{aligned}
& R_{b s 1}=-\left[1+(\partial z / \partial r)^{2}\right]^{1.5} /\left(\partial^{2} z / \partial r^{2}\right) \text { and } \\
& R_{b s 2}=r\left[1+(\partial r / \partial z)^{2}\right]^{0.5} .
\end{aligned}
$$

The root-mean-square deviation of the air pressure along the Taylor bubble surface, i.e.

$$
R M S D_{p}=\sqrt{\left[\sum_{i=1}^{i_{\max }}\left(\left.p_{g, i}\right|_{b s}-\left.p_{g, 1}\right|_{b s}\right)^{2}\right] /\left(i_{\max }-1\right)},
$$

was employed to indicate whether or not the pressure distribution of the air was uniform. Herein, the symbol $i$ refers to the number of the gridline vertex on the Taylor bubble surface, shown in Fig.2b. The location $i=$ 1 is the location of the Taylor bubble nose and the maximum value of $i$ is 75 for this study. It is clear that $R M S D_{p}$ will equal zero if the pressure distribution of the air is uniform. However, the uniform distribution of the air pressure inside the Taylor bubble is practically difficult to be obtained, the minimum value of $R M S D_{p}$ was alternatively exploited.

The grid search method was selected in order to determine the appropriate values of $\alpha_{1}$ and $\alpha_{2}$. At first, a searching domain was initially set to be a range, bounded within $\alpha_{1 \min , 1} \leq \alpha_{1} \leq \alpha_{1 \max , 1}$ and $\alpha_{2 \min , 1} \leq \alpha_{2} \leq \alpha_{2 \max , 1}$. These minima and maxima must be properly guessed to ensure that the first searching domain covered the appropriate values of $\alpha_{1}$ and $\alpha_{2}$. The first searching domain was next discretized to be a coarse searching grid with selected values of $\Delta \alpha_{1,1}$ and $\Delta \alpha_{2,1}$. Next, a pair of $\alpha_{1}$ and $\alpha_{2}$ was selected from this coarse searching grid to create the Taylor bubble shape for a computational domain with Eq.(2.3) and Eq.(2.4). Next, a flow simulation was launched until it converged to a steady state and therefore a distribution of liquid pressure on the Taylor bubble surface was obtained for being substituted to Eq.(4.1) in order to calculate a distribution of the gas pressure inside the Taylor bubble. Next, Eq.(4.5) was exploited to calculate an $R M S D_{p}$. Then, another pair of $\alpha_{1}$ and $\alpha_{2}$ was selected from the coarse searching grid and the procedure was repeated until all the pairs of $\alpha_{1}$ and $\alpha_{2}$ from the coarse searching grid were selected. Finally, the minimum value of $R M S D_{p}$ would indicate the appropriate Taylor bubble shape and the appropriate values of $\alpha_{1}$ and $\alpha_{2}$, too. In the event that the accuracy of this solution was not sufficient, a finer searching grid, bounded in $\alpha_{1 \text { min,2 }} \leq \alpha_{1} \leq \alpha_{1 \max , 2}$ and $\alpha_{2 \min , 2} \leq \alpha_{2} \leq \alpha_{2 \max , 2}$, might be created with $\Delta \alpha_{1,2} \approx 0.5 \Delta \alpha_{1,1}$ and $\Delta \alpha_{2,2} \approx 0.5 \Delta \alpha_{2,1}$. The new minima and maxima were set as follows: $\alpha_{1 \min , 2}=\alpha_{1 a p p, 1}-\Delta \alpha_{1,1}, \alpha_{l \max , 2}=\alpha_{1 a p p, 1}+\Delta \alpha_{1,1}, \alpha_{2 \min , 2}=\alpha_{2 a p p, 1}-\Delta \alpha_{2,1}$ and $\alpha_{2 \max , 2}=\alpha_{2 a p p, 1}+\Delta \alpha_{2,1}$. Then the searching process, mentioned above, might be repeated. The process was repeated until the significant figures of the appropriate $\alpha_{1}$ and $\alpha_{2}$ were equal to three. The procedure can be depicted as a flow chart in Fig.3. 


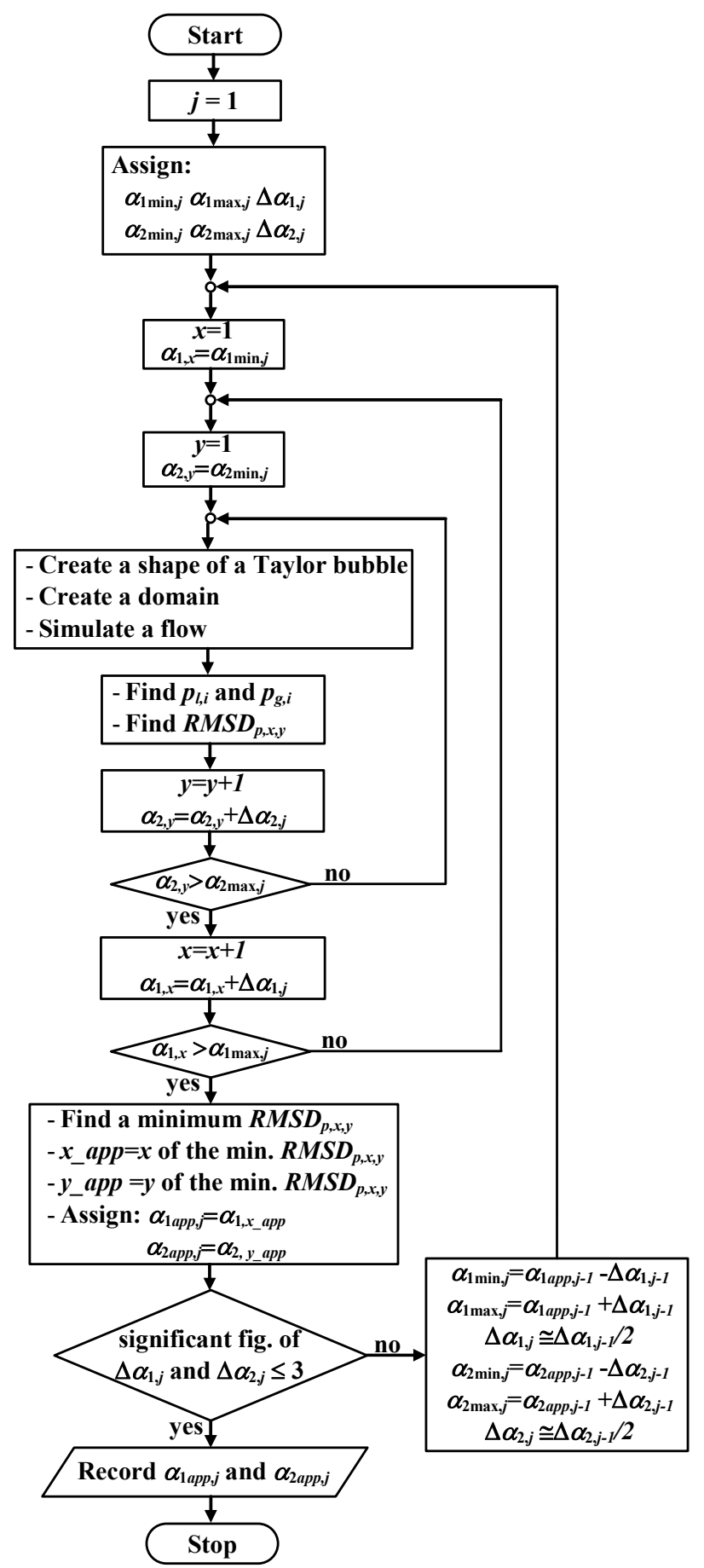

Fig.3. Flow chart for the procedure of finding appropriate $\alpha_{1}$ and $\alpha_{2}$.

\section{Result}

After simulating, all the appropriate $\alpha_{1}$ and $\alpha_{2}$ from 6 different $\sigma$ were obtained as presented in Tab.1. 
Table 1. Appropriate alphas and corresponding parameters in each investigating case.

\begin{tabular}{c|c|c|c|c|c}
\hline $\begin{array}{c}\sigma \\
(\mathrm{N} / \mathrm{m})\end{array}$ & $\alpha_{1}$ & $\alpha_{2}$ & $F r_{D}$ & $E o_{D}$ & $\begin{array}{c}w_{b} \\
(\mathrm{~m} / \mathrm{s})\end{array}$ \\
\hline 0.001 & 1.43 & -15.3 & 0.351 & 24500 & 0.246 \\
\hline 0.030 & 1.43 & -14.9 & 0.351 & 818 & 0.246 \\
\hline 0.120 & 1.43 & -14.5 & 0.350 & 204 & 0.245 \\
\hline 0.600 & 1.52 & -13.6 & 0.329 & 40.8 & 0.230 \\
\hline 1.200 & 1.71 & -18.6 & 0.275 & 20.4 & 0.193 \\
\hline 2.000 & 2.29 & -27.5 & 0.191 & 12.3 & 0.134 \\
\hline
\end{tabular}

In order to investigate the influence of the surface tension, shapes of a Taylor bubble were created with the appropriate $\alpha_{1}$ and $\alpha_{2}$ in Tab.1 for comparing in Fig.4a. Only the shape of a Taylor bubble in the case that $\sigma=2.000 \mathrm{~N} / \mathrm{m}$ was apparently the thickest but it was quite difficult to see the difference among the shapes of a Taylor bubble in other cases. Therefore the area, confined in the dashed rectangle of Fig.4a, was enlarged to make the difference among all shapes of a Taylor bubble to be clearer as shown in Fig. $4 \mathrm{~b}$.

There was no significant change of the Taylor bubble's shapes when $\sigma=0.001 \mathrm{~N} / \mathrm{m}, \sigma=0.030 \mathrm{~N} / \mathrm{m}$ and $\sigma=0.120 \mathrm{~N} / \mathrm{m}$ in accordance with Fig. $4 \mathrm{~b}$, the surface tensions are 120 times different though. But after this point, the shape of a Taylor bubble would be blunter if $\sigma$ was increased. This was consistent with [10] which stated that a Taylor bubble would be slenderer if Eo decreased. Besides, the shape of a Taylor bubble, created by the Dumitrescu-and-Taylor model, was also presented as a reference in Fig.4. It was found that the shape of a Taylor bubble created by the Dumitrescu-and-Taylor model was surrounded by the simulated results and close to the one of the case when $\sigma=1.200 \mathrm{~N} / \mathrm{m}$.

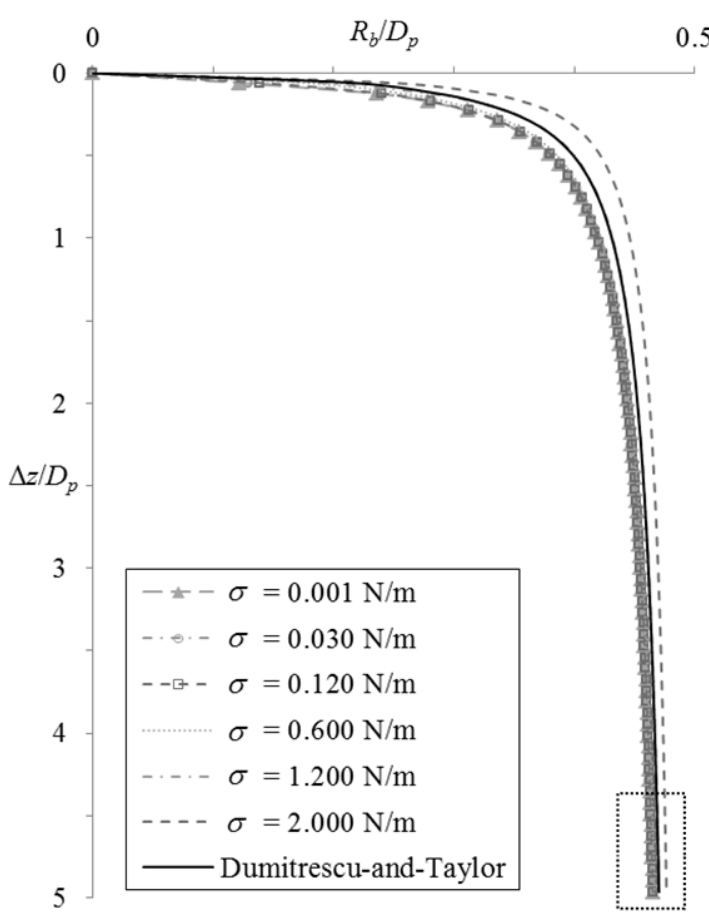

(a)

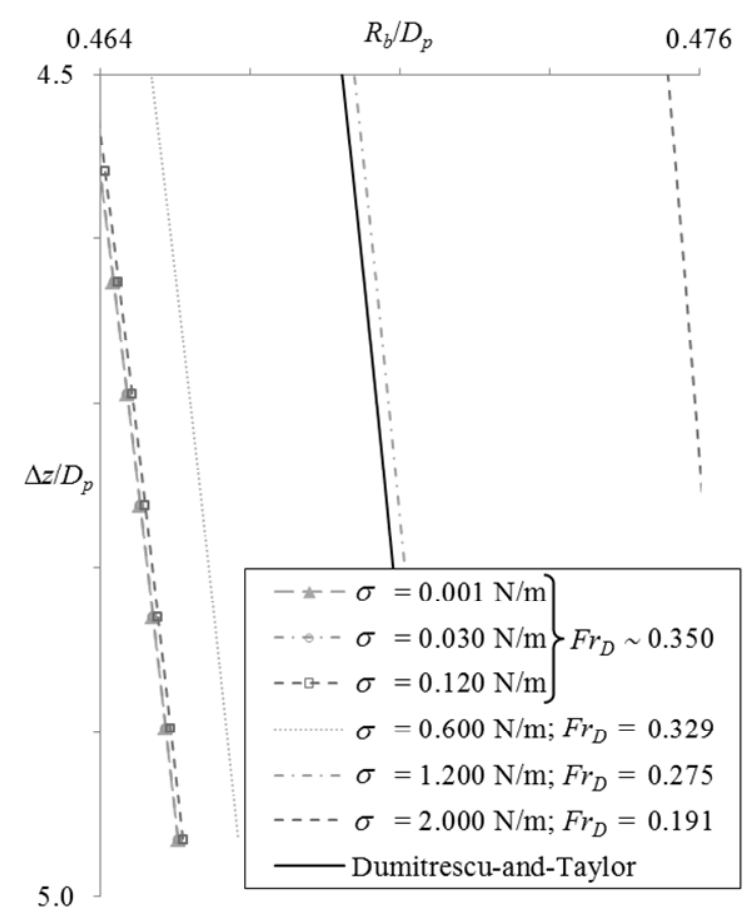

(b)

Fig.4. Influence of surface tension on the shapes of a Taylor bubble. 


\section{Discussion}

The influence of $\sigma$ was likely to be obvious when $\sigma$ exceeded the value (between 0.120 and 0.600 in this study) in accordance with Fig.4 and Tab.1. The reason of this issue may be explained by considering the conservation of mass in the control volume, confining a unit of a slug flow as shown in Fig.5.

Assuming that the considered condition is steady, the continuity equation, governing the control volume can be reduced to be

$$
\rho_{l} w_{b} \pi R_{p}^{2}=\left[\int_{R_{b}}^{R_{p}} \rho_{l} w_{l} 2 \pi r d r\right]_{\Delta z=5 D_{p}} .
$$

Since the flow in the falling film region was turbulent, the velocity profile was similar to a uniform distribution along the $r$-axis. This simplifies the right-hand-side term of Eq.(6.1) as follows.

$$
\begin{aligned}
& \left.\rho_{l} w_{b} \pi R_{p}^{2} \approx \rho_{l} \bar{w}_{l}\right|_{\Delta z=5 D_{p}} \pi\left(R_{p}^{2}-\left.R_{b}^{2}\right|_{\Delta z=5 D_{p}}\right) \\
& \left.R_{b}^{2}\right|_{\Delta z=5 D_{p}} \approx\left(1-w_{b} /\left.\bar{w}_{l}\right|_{\Delta z=5 D_{p}}\right) R_{p}^{2}
\end{aligned}
$$

Substituting Eq.(1.2) into Eq.(6.2) yields

$$
\left.R_{b}^{2}\right|_{\Delta z=5 D_{p}} \approx\left(1-F r_{D} \sqrt{g D_{p}} /\left.\bar{w}_{l}\right|_{\Delta z=5 D_{p}}\right) R_{p}^{2}
$$

Considering Eq.(6.3), it is clear that if $F r_{D}$ is reduced, $R_{b}$ will trend to be greater. This leads a smaller cross sectional area of the mass efflux in Fig.5 and, then, $\left.\bar{w}_{l}\right|_{\Delta z=5 D_{p}}$ must be greater to maintain the balance of the mass influx and the mass efflux of the control volume. In other words, it can be stated that reducing $\operatorname{Fr}_{D}$ will eventually result in a greater $\left.\bar{w}_{l}\right|_{\Delta z=5 D_{p}}$ and these two factors (less $F r_{D}$ and greater $\left.\bar{w}_{l}\right|_{\Delta z=5 D_{p}}$ ) promote $R_{b}$ to be greater (a blunter Taylor bubble). Since $F r_{D}$ is a function of $\sigma$ as shown with Eq.(1.3) and Eq.(1.5), namely $F r_{D}$ will be reduced if $\sigma$ is increased as tabulated in Tab.1. This means that increasing $\sigma$ will result in a blunter shape of a Taylor bubble. It agrees quite well with [4] which concluded that $\sigma$ would play an important role if $E o_{D}$ was greater than 70 (between 40.8 and 409 in this study).

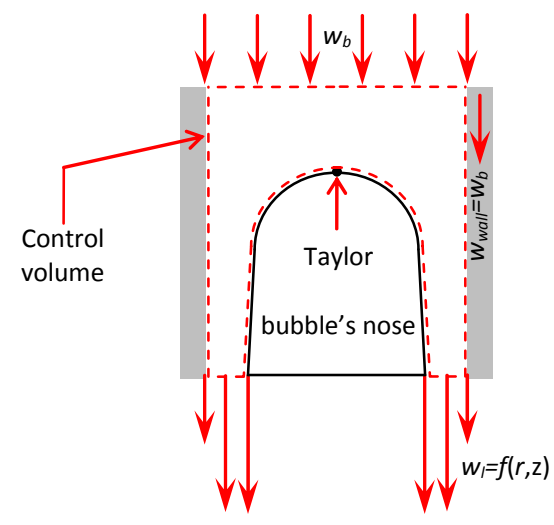

Fig.5. A diagram of a control volume, confining a slug flow unit. 


\section{Conclusions}

Under turbulent conditions, shapes of a Taylor bubble, in stagnant liquids of which surface tension is varied from 0.001 to $2.000 \mathrm{~N} / \mathrm{m}$, could be predicted by using Eq.(2.3) and Eq.(2.4) and the appropriate values of $\alpha_{1}$ and $\alpha_{2}$ in Tab.1.

Additionally, it was found that the influence of the surface tension began clear when the surface tension was greater than a value between 0.120 and $0.600 \mathrm{~N} / \mathrm{m}$, in which $F r_{D}$ began to be reduced. A supporting reason could be discussed with the continuity equation, which showed that reducing $F r_{D}$ would result in a greater velocity magnitude in the falling film region and eventually larger $R_{b}$, in other words, a blunter shape of a Taylor bubble.

\section{Nomenclature}

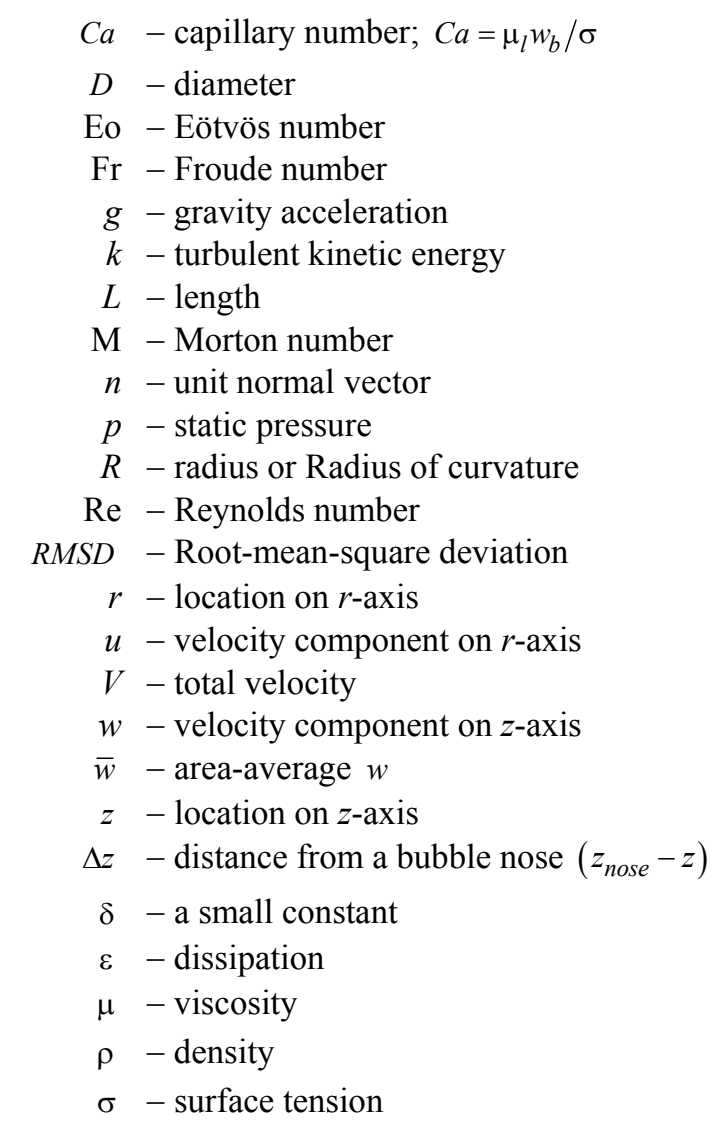

\section{Superscripts and Subscripts}

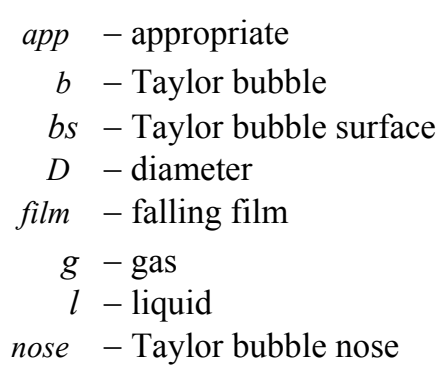




$$
\begin{aligned}
p & - \text { pipe } \\
s & - \text { slug } \\
t & - \text { terminal } \\
\text { wall } & - \text { pipe wall }
\end{aligned}
$$

\section{References}

[1] Grace J.R. and Clift R. (1979): Dependence of slug rise velocity on tube Reynolds number in vertical gas-liquid flow. - Chemical Engineering Science, vol.34, pp.1348-1350.

[2] Polonsky S., Shemer L. and Barnea D. (1999): The relation between the Taylor bubble motion and the velocity field ahead of it. - International Journal of Multiphase Flow, vol.25, pp. 957-975.

[3] Hayashi K., Kurimoto R. and Tomiyama A. (2011): Terminal velocity of a Taylor drop in a vertical pipe. International Journal of Multiphase Flow, vol.37, pp.241-251.

[4] White E.T. and Beardmore R.H. (1962): The velocity of rise of single cylindrical air bubbles through liquids contained in vertical tubes. - Chemical Engineering Science, vol.17, No. 5, pp.351-361.

[5] Barnea D. (1990): Effect of bubble shape on pressure drop calculations in vertical slug flow. - International Journal of Multiphase Flow, vol.16, No.1, pp.79-89.

[6] Tudose E.T. and Kawaji M. (1999): Experimental investigation of Taylor bubble acceleration mechanism in slug flow. - Chemical Engineering Science, vol.54, pp.5761-5775.

[7] Sotiriadis A.A. and Thorpe R.B. (2005): Liquid re-circulation in turbulent vertical pipe flow behind a cylindrical bluff body and ventilated cavity attached to a Sparger. - Chemical Engineering Science, vol.60, pp.981-994.

[8] Lertnuwat B. and Bunyajitradulya A. (2007): Effects of interfacial shear condition and trailing-corner radius on the wake vortex of a bubble. - Nuclear Engineering and Design, vol.237, No.14, pp.1526-1533.

[9] Nogueira S., Riethmuler M.L., Campos J.B.L.M. and Pinto A.M.F.R. (2006): Flow in the nose region and annual film around a Taylor bubble rising through vertical columns of stagnant and flowing Newtonian liquids. Chemical Engineering Science, vol.61, pp.845-857.

[10] Bugg J.D., Mack K. and Rezkallah K.S. (1998): A numerical model of Taylor bubbles rising through stagnant liquids in vertical tubes. - International Journal of Multiphase Flow, vol.24, No.2, pp.271-281.

[11] Mao Z-S. and Dukler A.E. (1990): The motion of Taylor bubbles in vertical tubes. I. A numerical simulation for the shape and rise velocity of Taylor bubbles in stagnant and flowing liquid. - Journal of Computational Physics, vol.91, No.1, pp.132-160.

[12] Mao Z-S. and Dukler A.E. (1991): The motion of Taylor bubbles in vertical tubes-II. Experimental data and simulations for laminar and turbulent flow. - Chemical Engineering Science, vol.46, No.8, pp.2055-2064.

[13] Kawaji M., DeJesus J.M. and Tudose G. (1997): Investigation of flow structures in vertical slug flow. - Nuclear Engineering and Design, vol.175, pp.37-48.

[14] Smith S., Taha T. and Cui Z. (2002): Enhancing Hollow Fibre Ultrafiltration Using Slug-Flow - a Hydrodynamic Study. - Desalination, vol.146, pp.69-74.

[15] Taha T. and Cui Z.F. (2004): Hydrodynamics of slug flow inside capillaries. - Chemical Engineering Science, vol.59, pp.1181-1190.

[16] Van Baten J.M., and Krishna R. (2005): CFD Simulation of Wall Mass Transfer for Taylor Flow in Circular Capillaries. - Chemical Engineering Science, vol.60, pp.1117-1126.

[17] Nigmatulin T.R. and Bonetto F.J. (1997): Shape of Taylor bubbles in vertical tubes. - International Communications in Heat and Mass Transfer, vol.24, No.8, pp.1177-1185.

[18] Dumitrescu D.T. (1943): Strömung an Einer Luftblase im Senkrechten Rohr. - Zeitschrift fur Angewandte Mathematik und Mechanik, vol.23, pp.139-149. 
[19] Lertnuwat B. (2015): Model for predicting the head shape of a Taylor bubble rising through stagnant liquids in a vertical Tube. - Thammasat International Journal of Science and Technology, vol.20, No.1, pp.37-46.

[20] Hout R.V., Bernea D. and Shemer L. (2001): Evolution of statistical parameters of gas-liquid slug flow along vertical pipes. - International Journal of Multiphase Flow, vol.27, pp.1579-1602.

[21] Hout R.V., Bernea D. and Shemer L. (2003): Evolution of hydrodynamic and statistical parameters of gas-liquid slug flow along inclined pipes. - Chemical Engineering Science, vol.58, No.1, pp.115-133.

[22] Shemer L. (2003): Hydrodynamic and statistical parameters of slug flow. - International Journal of Heat and Fluid Flow, vol.24, pp.334-344.

[23] Pinto A.M.F.R., Coelho Pinheiro M.N. and Campos J.B.L. (2001): On the interaction of Taylor bubbles rising in two-phase co-current slug flow in vertical columns: turbulent wakes. - Experiments in Fluids, vol.31, pp.643-652.

[24] Thulasidas T.C., Abraham M.A. and Cerro R.L. (1997): Flow patterns in liquid slugs during bubble-train flow inside capillaries. - Chemical Engineering Science, vol.52, pp.2947-2962.

[25] Cheng H., Hills J.H. and Azzorpardi B.J. (1998): A study of the bubble-to-slug transition in vertical gas-liquid flow in columns of different diameter. - International Journal of Multiphase Flow, vol.24, No.3, pp.431-452.

[26] Sun B., Wang R., Zhao X. and Yan D. (2002): The mechanism for the formation of slug flow in vertical gas-liquid two-phase flow. - Solid-State Electronics, vol.46, No.12, pp.2323-2329.

[27] Kytömaa H.K. and Brennen C.E. (1991): Small amplitude kinematic wave propagation in two-component media. International Journal of Multiphase Flow, vol.17, No.1, pp.13-26.

[28] Mayor T.S., Pinto A.M.F.R. and Campos J.B.L.M. (2007): Hydrodynamics of gas-liquid slug flow along vertical pipes in the laminar regimes-experimental and simulation study. - Industrial \& Engineering Chemistry Research, vol.46, pp.3794-3809.

[29] Ferziger J.H. and Peric M. (2002): Computational Methods for Fluid Dynamics. - Germany: Springer.

Received: July 4, 2017

Revised: December 6, 2017 